\title{
Overview of RS-25 Adaptation Hot-Fire Test Series for SLS, Status and Lessons Learned
}

\author{
Naveen Vetcha, ${ }^{1}$ Matthew B. Strickland, ${ }^{2}$ Kenneth D. Philippart ${ }^{3}$ and Thomas V. Giel Jr. ${ }^{4}$ \\ Jacobs Space Exploration Group/ESSCA/NASA Marshall Space Flight Center, Huntsville, AL, 35812 USA
}

This paper discusses the engine system design, hot-fire test history and analyses for the RS-25 Adaptation Engine test series, a major hot-fire test series supporting the Space Launch System (SLS) program. The RS-25 is an evolution of the Space Shuttle Main Engine (SSME). Since the SLS mission profile and engine operating conditions differ from that experienced by the SSME, a test program was needed to verify that SLS-unique requirements could be met by the adapted legacy engines. A series of 18 tests, including one engine acceptance test, was conducted from January 2015 to October 2017, to directly support Exploration Mission-1 (EM-1), the first flight of SLS. These tests were the first hot-firings of legacy SSME hardware since 2009. Major findings are described along with top level overview of the engine system.

\section{Introduction}

On October 11, 2010 President Barack Obama signed into law the National Aeronautics and Space Administration (NASA) authorization act of 2010. The law directed NASA to "develop a heavy lift launch vehicle as a follow on to the Space Shuttle that can access cis-lunar space and the regions of space beyond low-Earth orbit in order to enable the United States to participate in global efforts to access and develop this increasingly strategic region." The minimum capability requirements for this launch vehicle are:

- Capability to lift payloads weighing between 70 to 100 metric tons into low-Earth orbit (LEO) in preparation for transit for missions beyond LEO,

- Capability to carry an integrated upper Earth departure stage bringing the total lift capability to 130 metric tons or more,

- $\quad$ Capability to lift the Orion Multi-Purpose Crew Vehicle (MPCV), and

- Capability to serve as a backup system for supplying and supporting International Space Station (ISS) cargo requirements or crew delivery requirements not otherwise met by available vehicles.

Immediately after the enactment of the law, NASA started reviewing various potential vehicle designs. After months-long comprehensive reviews, on September 14, 2011 NASA selected and announced the design of a new Space Launch System (SLS) that would take astronauts further into space than ever before. The SLS would carry human crews beyond LEO in the Orion MPCV. The rocket would use a liquid hydrogen and liquid oxygen propellant system, where RS-25 engines (an evolution of the Space Shuttle Main Engine, SSME) will provide the core stage propulsion.

Three versions of the SLS launch vehicle were planned: Block 1 (initial lift capability of 70 metric tons), Block 1B (evolved lift capability of 105 metric tons) and Block 2 (evolved lift capability of 130 metric tons). Each vehicle configuration would use the same core stage design with four main engines. To be more affordable, initial flights would use modified SSME engines recovered from the Space Transportation System (STS) Shuttle Program (RS-25 Adaptation engines). Later flights are expected to use a more affordable version of the engine currently being developed and manufactured under the RS-25 Production Restart program.

\footnotetext{
${ }^{1}$ Liquid Propulsion Analyst, ERC Inc/Jacobs Space Exploration Group, AIAA Senior Member.

${ }^{2}$ Senior Propulsion Engineer, Jacobs Space Exploration Group, AIAA Senior Member.

${ }^{3}$ Team Lead, Liquid Propulsion Systems, BRC/Jacobs Space Exploration Group, AIAA Associate Fellow.

${ }^{4}$ Senior Propulsion Engineer, ERC Inc/Jacobs Space Exploration Group, AIAA Associate Fellow.
} 
RS-25/SSME is a reusable, fuel-rich staged-combustion engine. It is a liquid-propellant rocket engine that uses liquid hydrogen as the fuel and liquid oxygen as the oxidizer. The engine is capable of attaining a vacuum thrust of over 512,000 pounds which is equivalent to 12 million horsepower. The regeneratively-cooled engine also features high performance fuel and oxidizer turbopumps that develop 69,000 horsepower and 25,000 horsepower, respectively. SSMEs were the only large rocket engines to ever achieve one million total seconds of operation (with a reliability of 0.9996) consuming 300 million gallons of propellant, and they operated safely and successfully on all 135 Space Shuttle flights. During the flights, the engines had a nominal burn time of approximately 500 seconds at $104.5 \%$ of rated power level (RPL).

The goal of the RS-25 Adaptation Engine program was to enable utilization of the remaining SSME assets to provide first stage boost propulsion to the SLS. Four RS-25 engines will power each SLS core stage. The major focus of the Adaptation program was to certify the modified RS-25 configuration, including a new engine controller operating the heritage engines at the SLS operating conditions. A comprehensive hot-fire testing program was planned that employed two development and two flight engines, which would be tested over a range of operating conditions sufficient to demonstrate the capability to meet mission requirements and certify six flight controllers. Plans called for a minimum of seven starts and 3500 seconds of hot-fire operation on one development engine, one start and 500 seconds of hot-fire operation on two flight engines, and nine starts and 4500 seconds of hot-fire operation on a second development engine. The majority of the hot-fire time would occur at 109 percent power level, which was the emergency power level specified in the STS program but is planned as the nominal power level for SLS. In the test program, some power level excursions to 104.5 percent, 100 percent, 95 percent, and 80 percent would occur as warranted by the individual test objectives. The 18 Adaptation hot-fire tests were performed at the NASA Stennis Space Center (SSC) from January 2015 to October 2017. The engines were tested at sea-level conditions on the A-1 test stand and almost 9,000 seconds of hot-fire test time were accumulated on developmental and flight engines.

Extensive effort went into collecting the data needed to anchor several engine system performance models. Such data included flowmeter calibrations, wet and dry thrust calibrations, measurement of inlet pressure gains and exploration of the effect of control orifice size and flow coefficients. The data were provided to engine modelers and in several instances, improvements were made in the models in time to influence subsequent engine test planning. The ability to rapidly turn around a priori performance predictions using models anchored with recent hot-fire test data was an important result of the program. These models are now being carried forward for use on the recentlyinitiated RS-25 Production Restart hot-fire test series.

In addition to supporting the SLS goals and milestones, the extensive hot-fire testing program provided numerous benefits and engineering "lessons learned" that are directly applicable to on-going and future liquid propulsion test programs. The RS-25 test program leveraged the skills developed during the J-2X hot-fire test program and evolved many of the nascent analytical tools from that test program. A new generation of liquid rocket test engineers has been trained and gained valuable skills and experience that will pay dividends for NASA and the United States in the RS25 Production Restart test series and future engine test and development programs.

This paper provides an overview of the RS-25 Adaptation ground test series that were used to collect development and verification data.

\section{System Requirements}

The primary mission of the RS-25 engine will be to provide propulsion for the SLS Core Stage. To fulfill this mission, the RS-25 engine will be started at sea level and will shut down at altitude conditions after approximately 500 seconds of operation at a primary thrust level of 512,000 pounds (109 percent of rated thrust). Engine requirements are summarized in Figure 1 below.

As the mission requirements for SLS are different from that of STS, several changes were needed to move from SSME to RS-25. For example, on the Space Shuttle external tank, the top of the LOX tank is about 150 feet above the engine interface whereas on SLS core stage, the top of the LOX tank is about 200 feet above the engine interface resulting in higher LOX inlet pressure. Some other major changes include design of new controller which operates using SLS power sources, changes to sensor monitoring, new harnesses to accommodate the new controller, changes to engine chill down procedures, LOX loading, LOX and LH2 bleed flow configurations. 


\author{
Vacuum Thrust \\ -Rated $=470,000 \mathrm{lbf}$ \\ -Precision $= \pm 6000 \mathrm{lbf}$ \\ -Closed-loop control \\ Minimum Vacuum Isp \\ $451.3 \mathrm{~s}$ (at $109 \%$ rated thrust) \\ Mixture Ratio \\ -Nominal $=6.00$ \\ -Precision: \\ $\pm 1.7 \%$ ( $65 \%$ to $90 \%$ rated thrust) \\ $\pm 1 \%$ ( $90 \%$ to $109 \%$ rated thrust) \\ -Closed-loop control \\ Engine Gimbal $=8^{\circ}$ circle
}

Engine Throttling

Steps $1 \%$ between $65 \%$ to $109 \%$

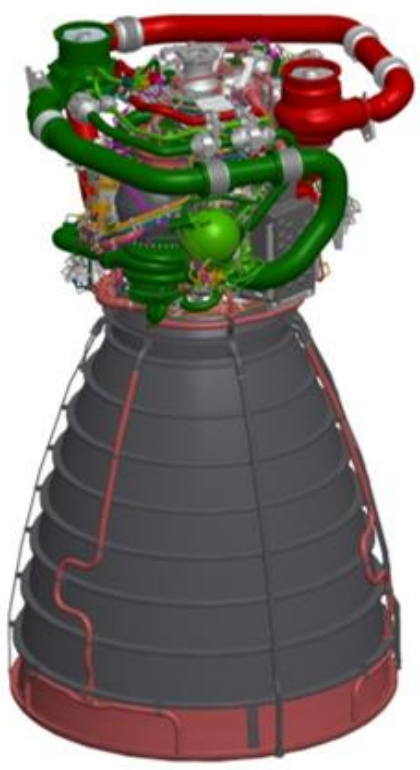

of rated thrust

Engine Mass $=8280 \mathrm{lbm}$

Engine Dimensions = 94" D X 167" L

Operational Life (Post delivery)

-6 starts, 2500 seconds ( $1^{\text {st }}$ and $2^{\text {nd }}$ SLS

flight)

-3 starts, 1100 seconds ( $3^{\text {rd }}$ and $4^{\text {th }}$ SLS

flight)

Engine Control system

-Electronic controller and software

-Reprogrammable

Fig. 1 RS-25 Adaptation engine requirements overview (image courtesy: Aerojet Rocketdyne)

\section{Component DDT\&E/Controller Development}

As mentioned earlier, the RS-25 Adaptation Engine program for SLS utilizes the remaining SSME assets to provide first stage boost propulsion to the SLS. The only engine component that was upgraded was the Engine Controller Unit (ECU) which is shown in Figure 2. The Engine Control (EC) system is composed of the ECU (comprised of hardware and software) and the new cabling/harnesses needed for RS-25. The EC provides command, control and data interface function between the engine and the vehicle.

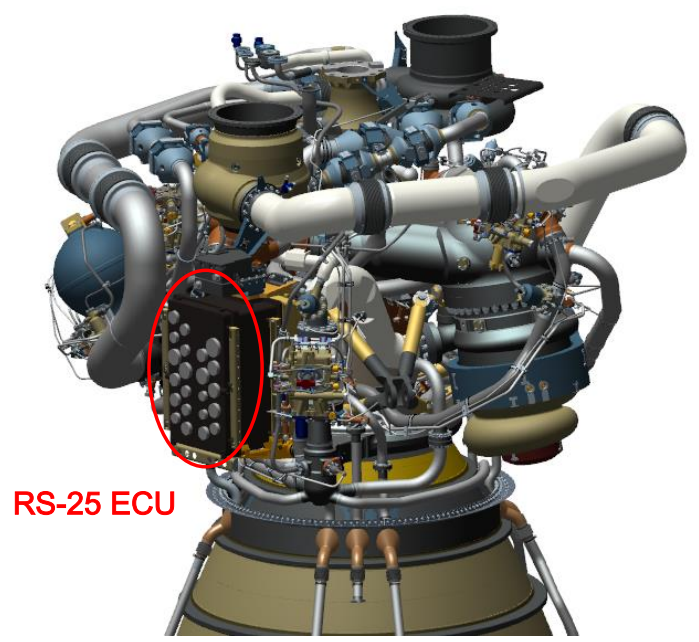

Fig. 2 RS-25 Engine Controller Unit mounted on the engine

As listed in Ref. [1], the functions of the ECU include:

- Receive and respond to commands from the vehicle.

- Provide closed-loop thrust and mixture ratio control of the engine during mainstage operation through position control of variable position propellant valves to the separate preburners.

- Manage engine state (i.e., start enable, start, mainstage, shutdown, etc.) transition and timing of effectors used during the different states. This includes the control of numerous purges and bleed flows. 
- Continuously monitor engine health.

- Provide data and health status to the vehicle flight controllers.

- Provide electrical power to all engine control elements, sensors and effectors.

The SSME heritage ECU was obsolete and incompatible with SLS vehicle architecture. The design and development of RS-25 ECU was leveraged from the knowledge gained during the development of the ECU for the J-2X upper stage engine for NASA's Constellation program. In effect, the new RS-25 ECU has J-2X derived system architecture, SSME engine interface and SLS vehicle interface (Figure 3).
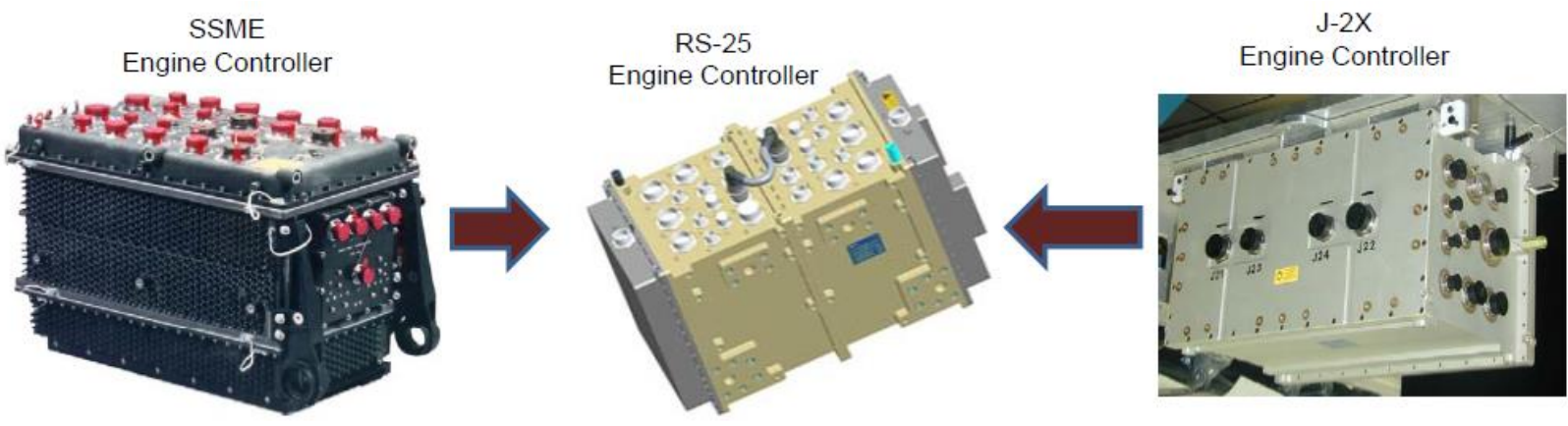

Fig. 3 RS-25 ECU development

RS-25 ECU software requirements were a combination of SSME and J-2X requirements. The software was developed using object-oriented C++ and verified in the Hardware-In-the-Loop (HIL) simulation lab located in NASA’s Marshall Space Flight Center.

A comprehensive test path was laid out to test the EC at each level of its assembly prior to green running the controller on a developmental engine. Figure 4 shows an overview of this test path.

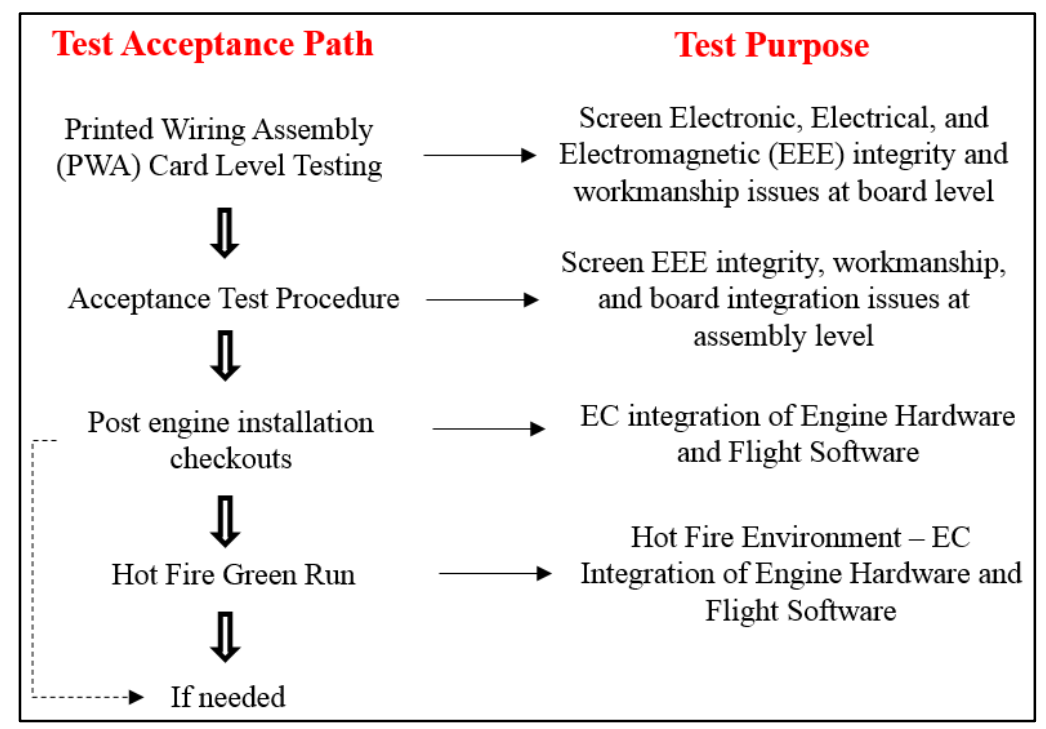

Fig. 4 EC Test Acceptance Path

Typical tests involved in each test phase are as follows:

PWA Card Level Testing: Electrical testing that can't be performed during EC box level testing.

Acceptance Test Procedure: Electrical Functional Testing (EFT), Vibration testing, Thermal testing, and Pressure Check Testing. 
Post engine Installation Checkouts: Actuator Calibration/Checkout, Preburner valve flow checks, Electrical/Pneumatic checkout, Servo Oscillation, and Firing Readiness Tests (FRT)

Hot Fire Green Run: Hot Fire test to requirements, and post-test Electrical/Pneumatic checkout

\section{System DDT\&E}

Within the envelope of the overall engine system design, there are very few changes required to adapt the engines from SSME to RS-25. Most of the engine hardware is already flight-certified and previously flown in STS missions, with known characteristics and demonstrated reliability. The Adaptation testing was mainly driven by vehicle changes, trajectory changes, and component changes. The objective of the testing program was to understand the engine performance in the new operating envelope. Following are some of the important changes:

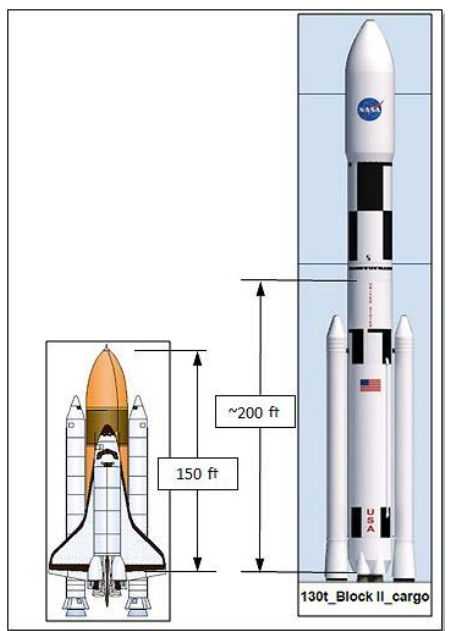

Fig. 5 LOX tank position STS vs SLS

\section{A. LOX Inlet Pressure}

The SLS LOX inlet pressure to the engines is higher as compared to STS due to increased tank height (Figure 6), increased acceleration and changes to ullage schedule. For the engine this translates into a new "start box" (boundaries of propellant temperature and pressure at engine start) and new main stage envelope (also known as the "run box") for oxidizer inlet conditions. The higher inlet pressures (Figure 5) during the start would result in increased flow into both preburners for the same start sequence valve positions and as a result there would be higher preburner temperature spikes at start which can cause turbine erosion and surface melting. For main-stage operation, the maximum run box inlet pressure requirement was increased by $\sim 80$ psia to meet the SLS thrust requirements. This can cause high pressures downstream of the Low Pressure Oxidizer Turbopump (LPOTP). Some engine configuration changes were suggested to slow the LPOP and reduce its discharge pressure.

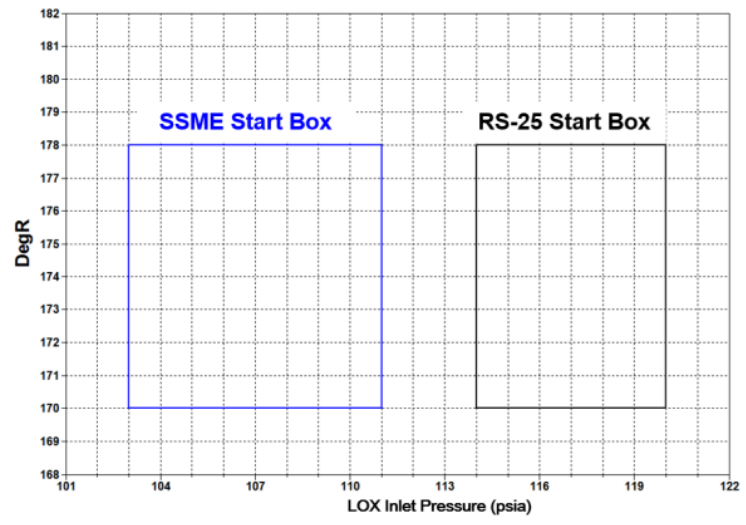

Fig. 6 LOX start conditions STS vs SLS 


\section{B. Fuel Inlet Pressure}

Fuel inlet pressure is slightly higher than the SSME start experience (Figure 7). This slight increase also affects the start sequence and temperature spikes. In addition to fluid height, vehicle ullage gaseous fuel flow, provided by the engine, has changed due to this engine exposure to higher inlet pressures during the mainstage operation.

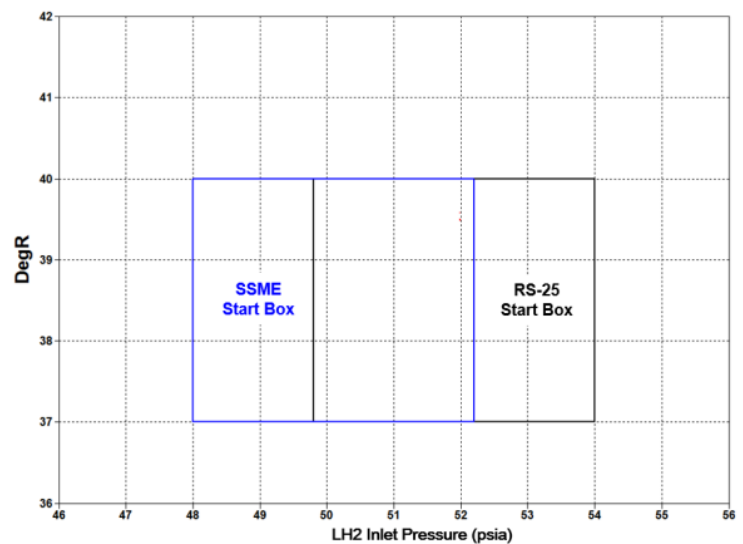

Fig. 7 Fuel start conditions STS vs SLS

\section{Tank Pressurization}

To maintain the ullage pressure in both the tanks, there is an increase in the tank pressurization flow as compared to STS. As the valve material is sensitive to the Gaseous Oxygen (GOX) temperature, the maximum temperature limits were reduced. Additional limits were put on interface pressure and temperature as a function of power level and flow rate. Fuel pressurization flow from the engines is also increased by the Gaseous Hydrogen (GH2) tap to drive the Core Auxiliary Power Unit (CAPU).

\section{Engine Controller}

As mentioned in the previous section the new engine controller is the main hardware change between SSME and RS-25. The new controller needed to be tested for start control, shutdown control, mainstage control, throttle response, and 109\% shutdown. Mainstage and shutdown control in both normal operating and emergency modes were tested.

Changes in the propellant supply systems from STS to SLS forced changes in the engine fuel and oxidizer start boxes to accommodate the higher inlet pressures as shown above. RS-25 does a boot-strap start sequence, increasing fuel pump then oxidizer pump power alternately while controlling both preburner temperatures to not exceed allowed turbine temperatures by controlling the Fuel Preburner Oxygen Valve (FPOV) and Oxidizer Preburner Oxygen Valve (OPOV) as well as the Chamber Coolant Valve (CCV). Because the FPOV and OPOV act as cavitating venturi elements to control the oxidizer flowrates to the preburners independent of the preburner pressure level, and a cavitating venturi flow depends on the both the inlet and saturation pressures and temperatures in a cryogenic fluid, changes in the start box pressures had to be accommodate by changes in the start sequence. A new start sequence was developed using detailed engine fluid network flow modelling, but a start sequence could not be developed to accommodate both the higher oxidizer inlet pressure and lower oxidizer inlet temperature changes of the SLS. To address this, heaters were added to the oxidizer feed system to maintain the oxidizer start box temperatures. The new start sequence for the final start boxes had to be verified across the range of the start boxes as part of the Adaptation test series.

In addition to the above, there are also other influences to account for in the engine test plan, such as the Low Pressure Fuel Turbopump (LPFTP) Higher Order Surge Cavitation (HOSC), additional nozzle heating due to the proximity of engine to Solid Rocket Boosters (SRB), and Adaptation software calibration for C2 and $\mathrm{K}_{\mathrm{f}}$. Ref. [1] discusses some more changes.

\section{Engine System Testing}

The A-1 test stand located in NASA's Stennis Space Center (SSC) was chosen to conduct all the RS-25 Adaptation series tests (Figure 8). This stand is capable of static firing a test article up to $33 \mathrm{ft}$ in diameter. It was designed for a maximum dynamic load of $1.1 \mathrm{M}-\mathrm{lb}$ vertical (up), $1.7 \mathrm{M}-\mathrm{lb}$ vertical (rebound), and $0.7 \mathrm{M}-\mathrm{lb}$ (horizontal) [2]. The stand is supplied with cryogenic fluids, hydrogen $\left(\mathrm{GH}_{2}\right)$, inert gases, industrial water, and electrical power 
necessary for test operations. $\mathrm{LOX}$ and $\mathrm{LH}_{2}$ are supplied to the stand from cryogenic transportation barges. $\mathrm{LH} 2$ and LOX are supplied to the test article from on-stand run tanks (simultaneous resupply from barge to tank is possible during extended duration test operations). Gaseous hydrogen $\left(\mathrm{GH}_{2}\right)$ is provided as a pressurant for the $\mathrm{LH}_{2}$ run tank systems. Gaseous nitrogen $\left(\mathrm{GN}_{2}\right)$ is provided as a pressurant for LOX run tank systems.

Test Stand A-1 was used to test the J-2X engine during the Constellation program. To prepare A-1 for the RS-25 Adaptation testing major changes had to be made to the test stand. All the propellant feed lines and other run lines were changed as per RS-25 requirements. Changes were also made to the Thrust Measurement System (TMS) to accommodate the RS-25 engine orientation and higher thrust loads. During this preparation a thorough inspection of all the runlines was performed. Magnification inspection of LOX runline remnant piping section revealed loosely attached metallic particles along the inner pipe wall. Additional on stand inspections revealed all LOX runline piping was suspect. Therefore all LOX spools (prefabricated sections of the piping system) were electropolished to remove metal particles. All spools passed on site evaluation after electropolishing.

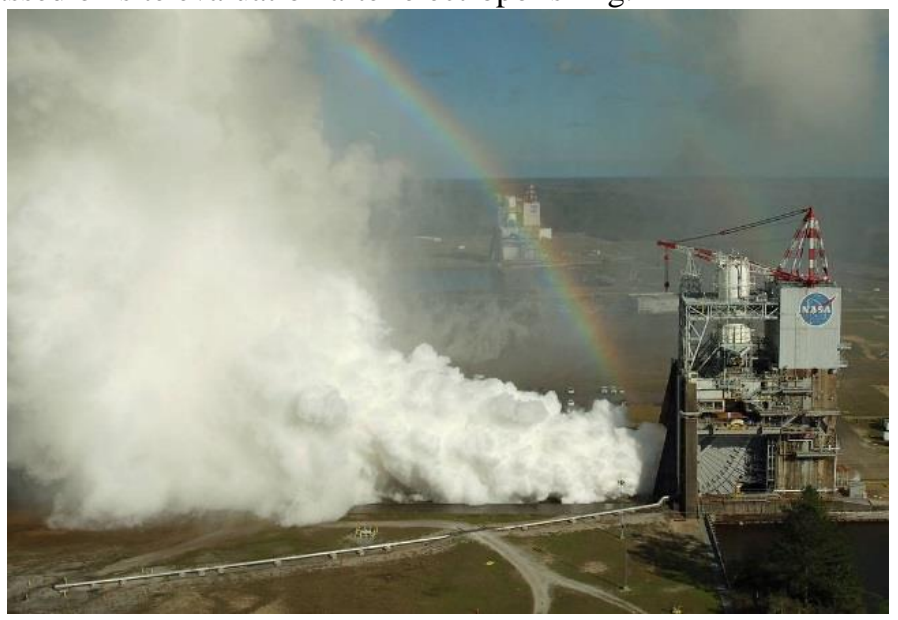

Fig. 8 RS-25 testing on A-1 Test Stand at Stennis Space Center (Image courtesy: NASA)

A total of 18 engine hot-fire tests were performed as part of the Adaptation test series between Jan, 2015 - Jan, 2018. Two of these tests were engine acceptance tests where flight engines were tested and tagged. Sixteen tests were performed on two development engines. Limits on the component hardware operation lifetime were one of the reasons for choosing two development engines instead of one. All the flight controllers were certified on the same engine to eliminate hardware changes as potential cause for differences. Figure 9 shows the amount of accumulated hot-fire time at each power level at the end of the test series. Most of the hot-fire testing accumulated time was performed at 109 percent and 80 percent power levels as the engines are required to operate mainly at those power levels during the flight.

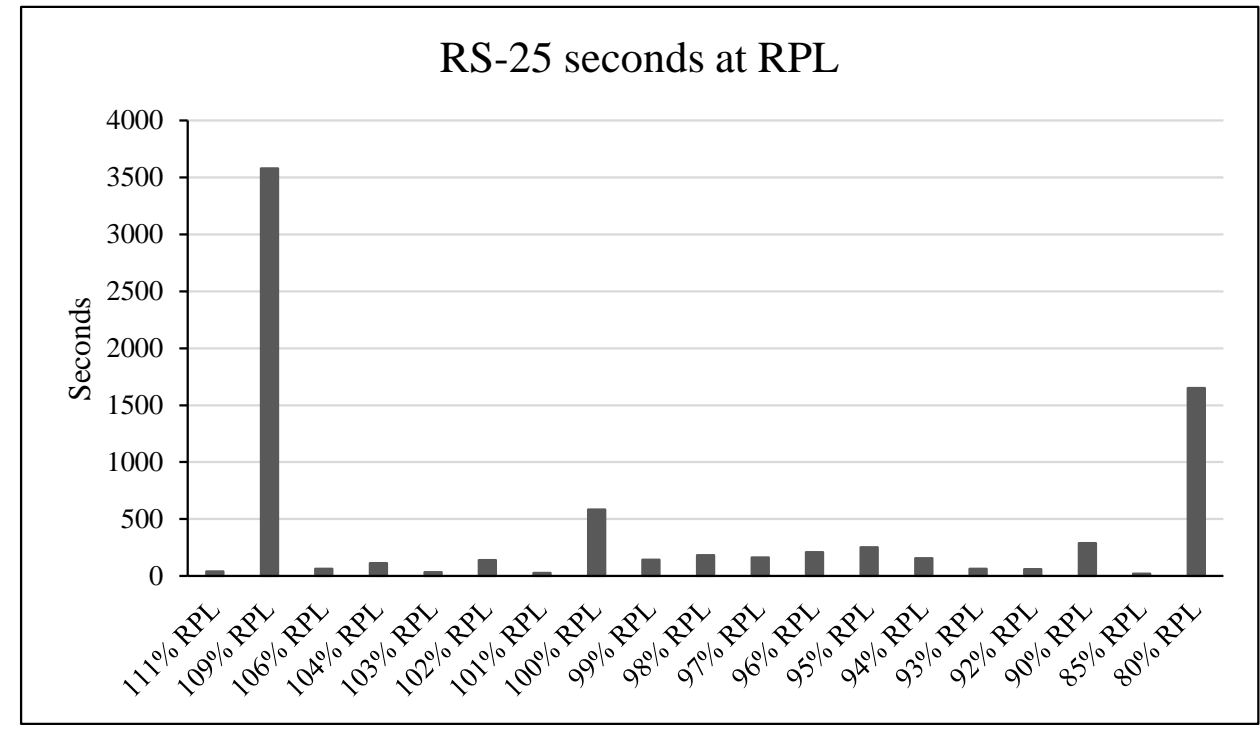

Fig. 9 RS-25 accumulated hot-fire time at different power levels 


\section{A. Engine Controller Green Run Testing}

As described in section III, each controller was tested at various levels of its assembly prior to performing the green run test. Foreign Object Debris (FOD) was discovered after green running one of the controllers. An investigation was launched promptly to identify the causes and to develop solutions. A series of short term and long term corrective actions were identified and included in the processes going forward. A total of six flight controllers were successfully green run tested in the Adaptation program.

\section{B. Start Sequence Testing}

During the first engine test of the engine system with the new controller design, issues were uncovered with the FPOV and OPOV valve position indications. The controller adjusts the valve positions using a feedback loop comparing commanded position and position measured by Rotary Valve Differential Transformers (RVDTs). Because RVDTs operate with an alternating current generated by controller oscillators, and redundant RVDTs are required for safety enhancement. With the new controllers processing signals from the 2 channels, this resulted in a beat frequency superimposed on the signal. The original controller design did not have a beat frequency, but the design modification to satisfy radiation hardening requirements did not design out this beat frequency. Discovery in testing of a significant beat frequency on all the valve position indications was required to be accommodated with a system solution applied to all the valves (except for the FPOV and OPOV) rather than a more costly controller redesign The beat frequency was sufficiently high enough that the start and shutdown sequences would operate essentially at the mean (desired) valve positions. However, the beat frequency interfered with maintaining main stage power level and mixture ratio control to meet requirements. Since the beat frequency is the same as the difference in frequency of the two driving oscillators, a small controller design addition of a master oscillator forced the redundant RVDT oscillators to be much closer in frequency giving a much lower beat frequency. This would allow power level and mixture ratio control to meet requirements, but would alter the start and shutdown sequence valve positioning. Fortunately, with additional model analyses the changes in shutdown sequence were shown to be inconsequential unless the amplitude of the beat oscillations was more than 1 percent. The analyses also indicated that changes in start sequence valve positioning, if the amplitude of the beat oscillations was less than 0.4 percent, could still be implemented to mitigate start spikes and poor oxidizer preburner combustion. Thus a system solution could be implemented, with only a slight increased risk of a premature shutdown.

\section{Conclusion}

The RS-25 Adaptation test series successfully demonstrated performance of the engines to SLS requirements. Flight controllers were green run tested for specifications and are either ready to be installed or already installed on the flight engines. The lessons learned through this test program are already being implemented in the RS-25 restart production program.

\section{Acknowledgments}

The authors wish to thank the following those who made valuable suggestions and helped in completion of this manuscript: Richard Ballard, Michael Nelson, John Butas and Tim Duquette.

\section{References}

[1] Ballard, R. O., "SSME to RS-25: Challenges of Adapting a Heritage Engine to a New Vehicle Architecture," $6^{\text {th }}$ European Conference for Aeronautics and Space Sciences (EUCASS), Krakow, Poland, 2015, URL: https://ntrs.nasa.gov/archive/nasa/casi.ntrs.nasa.gov/20150016499.pdf [retrieved 3 Jan 2018].

[2] Stennis Space Center, "Test Facilities Handbook," $4^{\text {th }}$ Edition, Sep 2001. 